\title{
EMANCIPAÇÃO INTELECTUAL E DEMOCRACIA: PARA UMA FILOSOFIA CRÍTICA DA EDUCAÇÃO A PARTIR DE JACQUES RANCIÈRE E PAULO FREIRE $^{1}$
}

\section{RESUMO:}

\author{
Fernando Gimbo ${ }^{2}$ \\ Universidade Federal de São Carlos (UFSCAR) \\ Universidade Federal do Cariri (UFCA) \\ (iD) https://orcid.org/0000-0002-9906-9379
}

Trata-se de propor, através da leitura conjunta de Jacques Rancière e Paulo Freire, uma filosofia da educação capaz de nos orientar em uma crítica da atual sociedade neoliberal. Tendo tal objetivo em vista, primeiramente exponho como a igualdade pode aparecer enquanto princípio a orientar nossas práticas educacionais. Com a afirmação da potência própria à inteligência é toda uma compreensão antropológica do homem que se desenha, compreensão essa que afirma o ser humano enquanto um ente que tem no aprendizado uma forma privilegiada de se relacionar e existir no mundo. Em um segundo momento, argumento que tal princípio da igualdade encontra uma complementariedade importante com a dialética entre opressores e oprimidos desenvolvida por Paulo Freire, explicitando o caráter político do princípio de igualdade de inteligências e sua necessária mediação social dentro de uma história marcada pelas relações de desigualdade. A partir disso, podemos propor uma ideia de educação não pautada na estratégia do investimento em capital humano e no decorrente crescimento econômico - pressuposto tão caro à racionalidade do capitalismo contemporâneo - mas sim na normatividade própria de uma antropologia e de uma filosofia da história democráticas e emancipadoras.

PALAVRAS-CHAVES: Educação; Crítica; Emancipação; Neoliberalismo; Democracia

\section{INTELLECTUAL EMANCIPATION AND DEMOCRACY: TOWARD A CRITICAL PHILOSOPHY OF EDUCATION FROM JACQUES RANCIÈRE AND PAULO FREIRE}

\begin{abstract}
:
The aim is to propose, through the joint reading of Jacques Rancière and Paulo Freire, a philosophy of education capable of orienting us in a critique of the current neoliberal society. Having such a goal in view, I first state how equality can appear as a principle to guide our educational practices. With the affirmation of the power proper to the intelligence is an entire anthropological understanding of the man who is drawn, understanding that affirms the human being as an entity that has in learning a privileged way of relating and existing in the world. In a second moment, I argue that such a principle of equality finds an important complementarity with the dialectic between oppressors and oppressed developed by Paulo Freire, explaining the political character of the principle of equality of intelligences and its necessary social mediation within a history marked by the relations of inequality. From this, we can propose an idea of education not based on the strategy of investing in human capital - a presupposition of the rationality of contemporary capitalism - but in the normativity proper to a democratic and emancipatory anthropology and philosophy of history.
\end{abstract}

KEYWORDS: Education; Critical emancipation; Neoliberalism; Democracy

\footnotetext{
${ }^{1}$ Este texto é o resultado da preparação da disciplina "Fundamentos sócio-histórico da educação", ministrada por mim no primeiro semestre de 2017. Tal disciplina compõe a grade curricular obrigatória do curso de licenciatura em filosofia da Universidade Federal do Cariri (UFCA), Ceará - Brasil. Por isso, dedico aos alunos que acompanharam tal curso essas reflexões.

${ }^{2}$ Doutorando em Filosofia pela Universidade Federal de São Carlos (UFSCAR), São Paulo - Brasil. Professor de Filosofia da Universidade Federal do Cariri (UFCA), Ceará - Brasil. E-mail: sepefernando@gmail.com
}

GIMBO, Fernando. Emancipação intelectual e democracia: para uma filosofia crítica da educação a partir de Jacques Rancière e Paulo Freire. Griot : Revista de Filosofia, Amargosa, Bahia, v.16, n.2, p.270-284, dezembro/2017. 
"Education is not preparation for life; education is life itself." - J. Dewey

\section{Introdução}

“Todos os homens têm igual inteligência" (RANCIÈRE, 2011, p.38). Podemos partir desta frase de Jacques Rancière uma vez que ela sintetiza a primeira questão a ser tratada neste artigo. Tal síntese se diz na conjunção expressa de duas questões: por um lado, a frase enuncia o princípio fundamental de sua filosofia da educação, a saber, o reconhecimento da inteligência como potência de conhecer comum a todos os seres humanos; ao mesmo tempo, ela parece recuperar um velho adágio idealista incapaz de resistir a uma confrontação mais rigorosa com a experiência empírica. Pois, em um primeiro momento, parece evidente que os sujeitos tanto tenham competências e aptidões diferentes quanto também as possuam em níveis qualitativamente díspares. Nesse caso, o enunciado parece trazer algo de uma visão ingênua e abstrata em que todos os homens seriam igualados em suas capacidades. Visão que estaria ultrapassada e que não mais corresponderia as exigências de especialização do conhecimento e de formação meritocrática que parece guiar nossos atuais dispositivos de ensino.

Contudo, gostaria de mostrar como compreender desta forma a tese da igualdade entre inteligências seria um crasso erro. Isso porque o que está em jogo no pensamento de Rancière é uma concepção sobre o ato de educar que, em seu desenvolvimento, resignifica nossa compreensão do conceito de inteligência. Para tanto, Rancière se apoia na experiência pedagógica de Joseph Jacotot $^{3}$ (2011). É em sua facticidade histórica e empírica que ele encontra elementos para desenvolver uma reflexão sobre a educação que ao fundamentar-se no princípio igualitário pode propor tanto uma nova pedagogia de ensino, como também uma ideia normativa renovada para a compreensão do que entender por uma educação bem-sucedida.

Dito isso, não é de surpreender que tal proposta encontre uma ressonância direta com a pedagogia freiriana do oprimido. Paulo Freire que, entre nós, foi quem melhor insistiu no caráter eminentemente igualitário da educação e em sua capacidade emancipadora, redefinindo a compreensão do que seria um processo de formação para a autonomia dentro dos quadros históricos de uma sociedade marcada pela desigualdade, como por exemplo as sociedades latinoamericanas. É certo que ao aproximar as considerações de Rancière e Paulo Freire meu intento não é meramente sublinhar certas coincidências entre as posições de ambos os pensadores, mas sim mostrar como lendo-os conjuntamente podemos iluminar um ao outro, desenvolvendo uma interpretação positiva capaz de contribuir dentro do debate pedagógico do séc. XXI e da filosofia social contemporânea.

Tendo tal objetivo em vista, primeiramente exponho como a igualdade pode aparecer enquanto princípio a orientar nossas práticas educacionais. Nesse momento, trata-se de entender a dinâmica que Rancière nomeia como "o círculo da potência" em oposição ao circuito da impotência característico da concepção tradicional de educação. Com a afirmação da potência própria à inteligência é toda uma compreensão antropológica do homem que se desenha, compreensão essa que afirma o ser humano enquanto um ente que tem no aprendizado uma forma privilegiada de se relacionar e existir no mundo. Em um segundo momento, argumento que tal princípio da igualdade encontra uma complementariedade importante com a dialética entre opressores e oprimidos desenvolvida por Paulo Freire, explicitando o caráter político do princípio de igualdade de inteligências e sua necessária mediação social dentro de

${ }^{3}$ Pedagogo francês do início do séc. XIX. Sua experiência educativa, fartamente documentada, é recuperada por Rancière em "O mestre ignorante" (2011), livro no qual me baseio para a exposição que se segue.

GIMBO, Fernando. Emancipação intelectual e democracia: para uma filosofia crítica da educação a partir de Jacques Rancière e Paulo Freire. Griot : Revista de Filosofia, Amargosa, Bahia, v.16, n.2, p.270-284, dezembro/2017. 
uma história marcada pelas relações de desigualdade. Dessa forma, intento desenvolver uma ideia de educação não pautada na estratégia do investimento em capital humano e no decorrente crescimento econômico - pressuposto tão caro à racionalidade do capitalismo contemporâneo ${ }^{4}$ mas sim na normatividade própria de uma antropologia e de uma filosofia da história democráticas e emancipadoras.

\section{A igualdade como princípio}

Se Rancière relembra Jacotot é porque encontra em sua experiência de ensino elementos para uma crítica da concepção tradicional de educação. Tal concepção Rancière nomeia através de seu significante maior: "o mestre". A educação pela palavra do mestre se dá através da transmissão do conhecimento. Sua dinâmica é, como diria Paulo Freire, basicamente "monológica e aquisitiva" (FREIRE, 1970, p.33-44). A autoridade daquele que conhece é exercida supostamente de forma legítima com o intuito de fazer com que aquele que ignora saia de sua ignorância. Processo marcado, então, pela "progressão destes sujeitos: conhecimento das matérias do programa para a maioria, a capacidade de se tornar mestre, por sua vez, para os melhores" (RANCIÈRE, 2011, p.10). Nesse caso, note-se como o mestre funciona como um paradigma filosófico e governamental. Seja em sua leitura conservadora, quanto liberal, a premissa é sempre a mesma: trata-se de partir de uma desigualdade constitutiva entre os seres humanos. Desigualdade na partilha do conhecimento, desigualdade de aptidões e níveis de inteligência. Perante tal quadro, à sociedade cabe a educação enquanto prática capaz de reduzir tais desigualdades, diminuindo a distância entre ignorantes e savants. Tal paradigma tornou-se tão triunfante que hoje ele aparece envolto em um halo de evidência e naturalização, o que dificulta em muito uma reflexão crítica sobre ele.

Pois bem, é exatamente tal naturalização que Rancière irá colocar em suspeita. Para tanto, ele parte de uma tese oposta: “(...) quem estabelece a igualdade como objetivo a ser atingido, a partir da situação de desigualdade, de fato a posterga até o infinito. A igualdade jamais vem após, como resultado a ser atingido. Ela deve ser sempre colocada antes" (RANCIÈRE, 2011, p.11). Proposição inquietante e, ao mesmo tempo, desconcertante. Pois, como defender a igualdade no campo do saber - já de início - quando a desigualdade parece ser um fato inegável no que diz respeito à partilha do conhecimento? Para bem compreender tal tese, primeiramente é preciso determinar em que nível a igualdade se coloca enquanto princípio. Ou seja, é preciso distinguir entre aquilo que se dá na experiência da aprendizagem e aquilo que é condição para tal experiência.

É um fato empírico e, portanto, constatado através de testes objetivos - por mais problemáticos que tais testes sejam - que a partilha do conhecimento humano se dá de forma diferente segundo as condições históricas, sociais, materiais e pedagógicas existentes. Parece ser evidente também que há um acúmulo histórico do conhecimento positivo, conhecimento que é passado intergeracionalmente através das estruturas de transmissão do saber científico. Negar isso seria apenas idealismo, ou mesmo ideologia da pior qualidade. Todavia, não é nesse nível que a tese da igualdade de inteligências se afirma.

Com ela, Rancière visa a condição de possibilidade para todo e qualquer ensino, isto é, aquilo que permite que a produção de conhecimento comece para que, então, o saber seja partilhado. Tomando a questão por esse viés percebemos como o que permite o saber não é a existência de um "Mestre", uma vez que nesse caso ele também deve ter aprendido de outro

${ }^{4}$ Sobre isso ver: FOUCAULT (2011), BROWN (2015), NUSSBAUM (2010), DARDOT e LAVAL (2016), GIMBO (2017).

GIMBO, Fernando. Emancipação intelectual e democracia: para uma filosofia crítica da educação a partir de Jacques Rancière e Paulo Freire. Griot : Revista de Filosofia, Amargosa, Bahia, v.16, n.2, p.270-284, dezembro/2017. 
mestre que terá que ter aprendido de outro e assim sucessivamente. O paradigma do mestre, quando levado às últimas consequências, cai em uma regressão ad infinitum incapaz de dar conta da gênese do conhecimento. Tudo se passa um pouco como em Espinosa que, contra Descartes, dizia que não há método para o conhecimento enquanto um conjunto de regras que todos deveríamos seguir, pois isso nos levaria a paradoxal situação de sempre ter "um martelo para fazer outro martelo" (SPINOZA, 1983 p.51-53). O que há na base de todo conhecimento, pelo contrário, é a inteligência enquanto potência para o saber. $\mathrm{E}$, uma vez que aprendemos uma única vez algo adequadamente - como por exemplo nossa língua materna -, então compreendemos como somos capazes de conhecer outras coisas. Como não há um único sujeito humano que nunca tenha aprendido nada, podemos afirmar que conhecer é uma capacidade essencial e intrínseca à vida humana, uma atividade fundante através da qual nos relacionamos e mediamos nosso ser com o mundo.

Sublinhe-se como dizer que há uma igualdade entre inteligências não é uma operação que visa homogeneizar as pessoas, pois partir do primado da igualdade significa simplesmente respeitar incondicionalmente o direito ao desenvolvimento singular - caso a caso - das inteligências. Isto é, a igualdade, enquanto princípio, não é constituída por uma unicidade homogênea da "Inteligência", mas sim pela univocidade heterogênea das inteligências. A igualdade se diz na multiplicidade e não no idêntico. Por isso, a igualdade é a antítese do desigual, não da diferença.

Recusando a identificação entre inteligência e saber, realizamos uma distinção filosófica entre a capacidade de conhecer e o conteúdo dessa capacidade. Isso porque se "não há ignorante que não saiba uma infinidade de coisas" é precisamente sobre "essa capacidade em ato que todo ensino deve se fundar" (RANCIÈRE, 2011, p.11). A astúcia de tal posição é que ela parte não da desigualdade empírica e histórica da partilha e posse do saber, mas sim da igualdade antropológica que nos diz, simplesmente, que todos os seres humanos são capazes de conhecer algo. Tal inversão de ponto de vista é prenhe de consequências uma vez que, nesse caso, a própria ideia de educar ganha outro sentido. Como explica Rancière, educar pode significar basicamente duas coisas:

[...] confirmar uma incapacidade pelo próprio ato que pretende reduzi-la ou, inversamente, forçar uma capacidade que se ignora ou se denega a reconhecer e a desenvolver toda as consequências desse reconhecimento (RANCIÈRE, 2011, p.12).

Quando partimos do dado da desigualdade acabamos sempre por perpetuá-la fazendo dela a própria regra do processo pedagógico. Tal escolha, como verificamos atualmente, se coaduna bem com as exigências mercantis e governamentais próprios aos dispositivos educacionais contemporâneos: a cada um segundo seu mérito, organização por aquisição de competência, postos de trabalho, salários e inserção no mercado de consumo como recompensa. O progresso pela educação, nesse caso, é indissociável da recolocação eterna da desigualdade, uma vez que esta funda e justifica os programas de educação do povo e, em última análise, a própria dinâmica social. A esse esquema caro às nossas sociedades Rancière dá o nome de embrutecimento.

Por outro lado, ao colocarmos a igualdade como princípio, alçamos a educação como algo próprio e intrínseco a todos os seres humanos, respeitando suas diferenças constitutivas. Ela deixa de ser um meio para o progresso, um investimento para a produção de mão de obra qualificada, para tornar-se um fim em si mesmo, fim entendido enquanto expressão da capacidade mais própria a cada sujeito. A ênfase, nesse caso, está na dignidade de cada vida inteligente e no seu direito ao pleno desenvolvimento. Tal compreensão do processo educativo Rancière denomina de emancipação, um pouco como Kant quando este insistia que todos os 
homens, através do uso livre de seu próprio entendimento, são capazes de pensarem por si e, consequentemente, se tornarem igualmente $\operatorname{livres}^{5}$ (KANT, 2005). Dessas distinções se segue um comentário definitivo:

Os amigos da igualdade não têm que instruir o povo, para aproximá-lo da igualdade, eles têm que emancipar as inteligências, têm que obrigar a quem quer que seja a verificar a igualdade de inteligências (RANCIÈRE, 2011, p.12).

A afirmação é eloquente e nela todo um programa emancipatório para educação se delineia. Mas, descontada sua beleza retórica, seus termos não são absolutamente claros. Devemos ainda nos perguntar: o que compreender por "verificar a igualdade de inteligência"? Ou ainda, qual o sentido da recusa em "instruir o povo"?

Nesse ponto sugiro que é preciso prosseguir de forma cautelosa, pois alguns enganos de leitura tornam-se possíveis. A principal interpretação a ser recusada, parece-me, é aquela que vê na afirmação do princípio da igualdade de inteligências uma posição suficiente para a concretização efetiva da igualdade entre os homens. Tal posição é indesejável porque ela acaba por imediatizar o princípio da igualdade bloqueando sua mediação pelo trabalho educativo, único capaz de concretizá-lo socialmente e institucionalmente. Em outras palavras, se a igualdade é condição necessária para o projeto de emancipação, ela não é condição suficiente por si. Caso contrário, há muito tempo a promessa da igualdade social já estaria realizada. Disso se segue, como insiste Rancière, que não basta apenas afirmar tal pressuposto; é preciso, constantemente, verificá-lo empiricamente, isto é, verificar sua adequação à experiência concreta instituindo suas condições de concretização. E isto apenas pode ser feito através da criação, reinvenção e construção de plurais processos educativos. Em uma palavra: como pensar uma educação que partisse desse pressuposto da igualdade de inteligências?

No fundo, o que está em jogo, aqui, é a necessidade pedagógica, política e social de se pensar a igualdade e a desigualdade para além de seus termos estritamente econômicos. Pois, é claro que uma educação de qualidade generalizada é capaz de reduzir as desigualdades materiais. Porém, não é essa a questão enfrentada. A questão é perguntar se a nossa educação não espelha - já de saída - tal desigualdade econômica, incrustando-a na relação entre homens no que toca a inteligência comum a todos e, portanto, destruindo aquilo que poderia dar origem a uma dinâmica de produção de igualdades reais. Nesse caso, trata-se de criticar um sobreinvestimento ideológico na educação que faria dela o meio através da qual os ignorantes poderiam se elevar um pouco e, aproximando das pessoas instruídas, melhorarem de vida. $\mathrm{O}$ problema com tal posição - que resume o que Rancière chama de "instruir o povo" - é que, descontado seu momento de verdade, ele parece "legitimar a visão oligárquica de uma sociedade-escola em que o governo não é mais do que a autoridade dos melhores da turma" (RANCIÈRE, 2011, p.15). No momento posterior, os melhores novamente irão relançar os programas de educação para os piores, reafirmando as distâncias que os separam, antropologizando e naturalizando as desigualdades históricas ${ }^{6}$. Paulo Freire, certa vez, chamou tal paradigma de educação como uma "educação bancária" (FREIRE, 1970, p.33-44).

Ora, se Rancière negasse a desigualdade factual sua tese apenas se mostraria impotente perante a situação do mundo. Ele reconhece essa desigualdade, mas critica que tal desigualdade

\footnotetext{
5 Sobre isso, sem dúvida uma das forças da argumentação rancieriana é que ela ao mesmo tempo em que realiza uma ácida crítica a certos ideais não refletidos caros à modernidade - como a ideia de progresso irrestrito por exemplo - ao mesmo tempo sustenta seu imperativo de emancipação do sujeito insistindo nas condições para a formação de um indivíduo livre.

6 Contemporaneamente, foi Pierre Bordieu que melhor descreveu tal processo sob o ponto de vista de uma sociologia da educação. A esse respeito ver, sobretudo, La distinction. Critique social du jugement (1979).
}

GIMBO, Fernando. Emancipação intelectual e democracia: para uma filosofia crítica da educação a partir de Jacques Rancière e Paulo Freire. Griot : Revista de Filosofia, Amargosa, Bahia, v.16, n.2, p.270-284, dezembro/2017. 
seja interiorizada pela escola e se torne, então, o alicerce e a justificativa central de legitimação da educação. Sintetizando o argumento: a desigualdade constatada empiricamente é uma desigualdade histórica e material; a igualdade de inteligências é uma igualdade antropológica e potencial.

A aposta que se faz através desta posição é de que ao partimos da igualdade das inteligências torna-se possível quebrar o circuito da impotência que produz e justifica a seleção e hierarquização social através dos processos educativos segregadores. Como um velho aluno de Louis Althusser, Rancière sabe que há uma dialética perversa no projeto de educação quando este não é visto segundo parâmetros de emancipação intelectual e política, mas como o organizador e legitimador incondicional das desigualdades que tecem e retecem o tecido social. Contemporaneamente, o que é ainda mais grave, podemos mesmo dizer que os aparatos ideológicos não mais respondem plenamente às exigências da razão estatal - como queria Althusser (1992) - mas sobretudo a universalização irrestrita dos valores de mercado, como explica Foucault (2010). Eis um motivo adicional para uma reflexão crítica aguda no que diz respeito aos valores primeiros a orientar nossos programas de educação.

Se Rancière recupera tal crítica a partir do princípio da igualdade é porque tal gesto, ao reconfigurar o ponto de partida da educação, permite outra compreensão da experiência de educar. Experiência que podemos definir como o estímulo à aprendizagem autônoma, como uma prática alicerçada em uma crença irrestrita na capacidade das pessoas aprenderem coletivamente através de uma auto-organização horizontal. Trata-se, em outras palavras, de criar condições para que um círculo de aprendizado mútuo e de reenvios incessantes entre outros seres inteligentes se estabeleça, constituindo uma dinâmica comunicacional, criativa e pragmática de atualização e expressão da inteligência humana. Imagem que recusa o caráter vertical, monológico, enciclopedista e regressivo do sistema tradicional, para insistir no "ensino universal" do qual todos somos capazes: "aprender qualquer coisa e a isso relacionar todo o resto, segundo o princípio de que todos os homens têm igual inteligência" (RANCIÈRE, 2001, p.38) É tal dinâmica, enquanto ideia reguladora da prática pedagógica, que Rancière chama de "o círculo da potência". Imagem que, de certa forma, simboliza sua reflexão sobre a educação.

Em tal dinâmica afirmativa da inteligência, a educação é emancipadora quando ela produz as condições para a expressão singular da inteligência com o outro. Isto é, não se trata de recusar a palavra do outro, ou que não tenhamos algo a aprender com o outro. Tal intepretação seria apenas um empobrecimento narcísico das relações mediadas pela inteligência. Trata-se, pelo contrário, de estabelecer pela educação um espaço de relação com a alteridade. Nas relações mediadas pela dinâmica do aprendizado mútuo, Rancière vê uma teia privilegiada para pensar uma forma de ser e estar com outrem que recusa o imperativo neoliberal da concorrência irrestrita, criando condições efetivas para o surgimento de laços sociais de solidariedade e autonomia partilhada.

A questão crítica fundamental, então, é: nossos dispositivos escolares funcionam como redutores da desigualdade, ou como verificadores da igualdade? Tal discussão não diz respeito simplesmente às técnicas de ensino e avaliação empregadas, mas principalmente a uma questão anterior e mais ampla estritamente ligada à política e à filosofia da educação: "saber se o ato mesmo de receber a palavra do mestre - a palavra do outro - é um testemunho de igualdade ou desigualdade" (RANCIÈRE, 2011, p.12). Essa tensão entre igualdade e desigualdade, entre antropologia e história social, entre emancipação e embrutecimento, desenha uma contradição que ocupa lugar central na exposição de Rancière: "a igualdade é fundamental e ausente" (RANCIÈRE, 2011, p.16). Em suma, podemos e devemos partir da igualdade, mas não podemos tê-la como efetivamente garantida; eis o dilema a ser enfrentado por uma filosofia da educação.

É aqui que a dialética freiriana entra em cena.

GIMBO, Fernando. Emancipação intelectual e democracia: para uma filosofia crítica da educação a partir de Jacques Rancière e Paulo Freire. Griot : Revista de Filosofia, Amargosa, Bahia, v.16, n.2, p.270-284, dezembro/2017. 


\title{
A democracia como fim
}

À primeira vista, a pedagogia do oprimido de Paulo Freire poderia ser lida em uma direção contrária à proposta de Rancière. Isso porque Freire não parece partir da igualdade entre inteligências, mas sim de uma desigualdade estruturante, a saber: a "contradição opressoresoprimidos" (FREIRE, 1970, p.16). Constatada tal contradição, o movimento emancipatório de sua pedagogia se diria na instauração de uma prática de ensino que colabore para o fim das relações de exploração do homem pelo homem. Logo, para uma leitura desatenta, tudo se passaria como se a pedagogia do oprimido caísse dentro das malhas críticas anteriormente expostas por Rancière - prolongamento da desigualdade ao colocar a igualdade apenas como fim - não obstante suas boas intenções.

Contudo, esse não é o caso. A diferença surge porque Freire, diferentemente de Rancière, parte sobretudo de um diagnóstico social. Para ele, um pensamento da educação começa pelo reconhecimento da contradição entre classes sociais, contradição que estrutura qualitativamente as relações humanas. Apenas perante tal quadro é que se torna possível perguntar: qual educação, qual pedagogia para este mundo? De forma sintética, diria que Freire toma como alicerce de sua reflexão um esquema sociológico em que a heteronomia dentro da qual a maior parte da população se encontra é o "dado" a ser transformado. O que se reconhece de início é uma desigualdade material e não de inteligências.

A esse respeito, o diagnóstico freiriano se coaduna diretamente com a posição crítica defendida por outro pensador sociológico da educação, a saber, Theodor Adorno:

\begin{abstract}
Se não quisermos aplicar a palavra "emancipação" num sentido meramente retórico, ele próprio tão vazio como o discurso dos compromissos que as outras senhorias empunham perante a emancipação, então por certo é preciso começar a ver efetivamente as enormes dificuldades que se opõem à emancipação nesta organização do mundo. [...] 0 motivo evidentemente é a contradição social; é que a organização em que vivemos continua sendo heterônoma, isto é, nenhuma pessoa pode existir na sociedade atual realmente conforme as suas próprias determinações; enquanto isso ocorre, a sociedade forma as pessoas mediante inúmeros canais e instâncias mediadoras, de um modo tal que tudo que absorvem e aceitam nos termos desta configuração heterônoma que se desviou de si mesma em sua consciência. É claro que isto chega até as instituições, até a discussão acerca da educação política e outras questões semelhantes. $\mathrm{O}$ problema propriamente dito da emancipação hoje é se e como a gente - e quem é "a gente", eis uma grande questão a mais - pode enfrentá-lo. (ADORNO, 1995, p.180-81)
\end{abstract}

Nessa passagem, Adorno segue paralelamente o diagnóstico freiriano explicitando os limites da aplicação da ideia de emancipação dentro da organização social moderna. A Pedagogia do oprimido, inclusive, poderia ser lida como uma resposta - ligada ao contexto sócio-histórico latino - a tal inquietação. Pois, segundo ela, é na educação popular enquanto prática de construção coletiva para a autonomia que reside a força capaz de efetuar um programa de emancipação da atual sociedade. À pergunta adorniana pelo "quem", Freire responde através do signo "povo". Mas não um povo dado, como uma categoria generalizante das individualidades postas em determinada sociedade. Se a pedagogia do oprimido é trabalho de formação e superação da contradição, tal povo apenas pode ser compreendido como um povo por-vir, como um vir-a-ser que encontra na educação o seu dínamo ${ }^{7}$.

\footnotetext{
7 Adorno também trabalha em seus textos sobre educação com a essa relação entre o processo de formação e a constituição do povo enquanto sujeito político. No fundo, trata-se em ambos os casos de insistir em um mesmo
}

GIMBO, Fernando. Emancipação intelectual e democracia: para uma filosofia crítica da educação a partir de Jacques Rancière e Paulo Freire. Griot : Revista de Filosofia, Amargosa, Bahia, v.16, n.2, p.270-284, dezembro/2017. 
Sobre isso, o primeiro ponto a ser destacado é como - para a pedagogia do oprimido tudo começa com a "instauração histórica do ser-menos": movimento marcado tanto pela divisão injusta do trabalho quanto pela acumulação desigual do capital e da propriedade privada (FREIRE, 1970, p.16). No caso da América Latina, é bom lembrar, movimento marcado também e sobretudo por um sistema mercantil de exploração sistemática e um rebaixamento cultural etnocida. Pois bem, nesta contradição estruturante das relações sociais, o que se diz é uma alienação daquilo que Freire chama de "ser-mais". Tal alienação é o que está, verdadeiramente, na origem da dialética freiriana.

É por isso que, como dito anteriormente, a pedagogia do oprimido não começa pela desigualdade de inteligências, uma vez que o ser-mais é, originariamente, a orientação mais essencial a todos os seres humanos. Com esse conceito, sugiro, Freire nada mais indica que a já vista disposição antropológica à aprendizagem. Ou seja, é inerente à toda vida inteligente um desenvolvimento qualitativo mediado pela capacidade de aprender autonomamente. Ser-mais é a forma humana de habitar o mundo, instituindo uma relação de compreensão com o entorno e com o outro, relação essa capaz de sempre se efetivar para além de si mesma. A vida como um educar-se constante, seu enriquecimento entendido nos termos de cultura, experiência, cognição e relações intersubjetivas mais lúcidas e maduras. Primeiro ponto da relação Freire-Rancière a ser destacado, ambos partem de uma antropologia filosófica - isto é, de uma ideia sobre a humanidade - que define a inteligência como o que é comum a todos os seres humanos. A desigualdade vem depois, é a posteriori e contingente, mas nem por isso deixa de ser factual e urgente $^{8}$.

O segundo ponto importante é a maneira como Freire explica a perpetuação da desigualdade pelo mesmo processo que visa suprimi-la. Para tanto, ele lança mão de duas linhas de raciocínio. Primeiramente, insiste - como Rancière - que os programas educacionais que tomam a educação como um meio que visa simplesmente diminuir as desigualdades, pelo mesmo processo as institui e as consolida: "Os opressores têm necessidade, para que sua "generosidade" continue tendo oportunidade de realizar-se, da permanência da injustiça. A "ordem social injusta é a fonte geradora", permanente, desta "generosidade" que se nutre da morte, do desalento e da miséria" (FREIRE, 1970, p.17). Ao mesmo tempo, Freire explora a ideia de uma identificação do oprimido com o opressor, processo responsável pela introjeção da imagem (aparência) do dominador na consciência moral e política do oprimido. Chegando a dizer que as classes menos favorecidas "hospedam" em si a classe dominante, a alienação daquilo que lhes é comum - das possibilidades próprias do ser-mais - explica o bloqueio histórico da emancipação individual e social.

\footnotetext{
diagnóstico: nossas democracias liberais seriam marcadas por um bloqueio na constituição do povo como sujeito capaz de determinar e realizar transformações emancipatórias na organização social: Daí esse comentário de Adorno: "Mas a democracia não se estabeleceu a ponto de constar da experiência das pessoas como se fosse um assunto próprio delas, de modo que elas compreendessem a si mesmas como sendo sujeitos dos processos políticos. Ela é apreendida como sendo um sistema entre outros, como se num cardápio escolhêssemos entre comunismo, democracia, fascismo ou monarquia; ela não é apreendida como identificando-se ao próprio povo, como expressão de sua emancipação. Ela é avaliada conforme o sucesso ou o insucesso, de que participam também os interesses individuais, mas não como sendo a unidade entre os interesses individuais e o interesse geral; e, de fato, a delegação parlamentar da vontade popular torna esta muitas vezes uma questão difícil nos modernos Estados de massa" (ADORNO, 1995, p.35-36).

${ }^{8}$ Como sabemos, na filosofia moderna o primeiro a derivar uma crítica social da desigualdade a partir de uma antropologia normativa foi outro filósofo ligado à educação: Jean Jacques-Rousseau. Evidentemente, a proposta aqui desenvolvida segue um caminho bem diferente da proposta da Rousseau e seu "bom selvagem", mas ainda assim devemos insistir que a estrutura geral do argumento é semelhante: é na história das sociedades e não na natureza humana que a desigualdade surge e se explica (ROUSSEAU, 2005).
}

GIMBO, Fernando. Emancipação intelectual e democracia: para uma filosofia crítica da educação a partir de Jacques Rancière e Paulo Freire. Griot : Revista de Filosofia, Amargosa, Bahia, v.16, n.2, p.270-284, dezembro/2017. 
O que encontramos aqui, no fundo, é uma teoria da ilusão necessária, uma alienação de si derivada da organização material do mundo que faz com que os indivíduos não sejam capazes de se reconhecerem entre si como homens livres, constituindo-se enquanto "sujeitos" somente a partir da busca heterônoma de uma suposta aparência de liberdade corporificada pela forma de vida hegemônica: "O seu ideal é, realmente, ser homens, mas, para eles, ser homens, na contradição em que sempre estiveram e cuja superação não lhes está clara, é ser opressores" (FREIRE, 1970, p.17). Como sabemos, o nome clássico dos discursos e práticas responsáveis por tal alienação de si é ideologia.

A saída de tal situação inicia-se através de um "reconhecimento crítico na razão desta situação" por parte dos oprimidos (FREIRE, 1970, p.18). Tradicionalmente, interpretamos tal movimento como a tomada de consciência capaz de orientar uma práxis transformadora. Seguindo a tradição dialética, Freire faz recurso ao movimento da dupla negação: primeiramente dos valores hegemônicos, da ordem estabelecida e da interiorização ideológica do outro; posteriormente da própria situação de desigualdade, da própria contradição entre classes, emancipando "a si mesmos e aos opressores" (FREIRE, 1970, p.18). Tal aufhebung, ao negar a situação de desigualdade histórica, cria as condições para a efetivação concreta da igualdade originária no estabelecimento de uma sociedade democrática e justa ao fim do percurso.

Para bem compreender tal percurso é preciso distinguir entre a contradição principal que força a reflexão freiriana e outras figuras que derivam de tal contradição, como é o caso de oprimido/opressores e educador/educando. A contradição principal, na verdade, é entre ser-mais $e$ ser-menos, o que assinala no centro do pensamento freiriano a presença de uma antinomia entre a capacidade de autonomia do indivíduo e as limitações e determinações impostas a ele através do meio. É do ser-mais, de uma certa ideia reguladora da realização humana, que Freire retira a negatividade necessária para exigir a crítica ao existente em vista de um por-vir. Recuperando, subjacentemente, o tema da Bildung e a epopeia do espírito que se aliena de si para posteriormente se reconciliar consigo mesmo, mas dando a tal narrativa uma inflexão históricomaterialista, a pedagogia do oprimido imagina a história da superação das desigualdades sociais através da efetivação concreta do princípio da igualdade por vias da educação. Tal concretização, sugiro, pode ser compreendido como o estabelecimento concreto das condições necessárias para uma democracia real. Ou seja, o pensamento freiriano constitui-se sobre o solo normativo de uma filosofia da história que afirma que "se a realidade social não existe por acaso, mas como produto da ação dos homens", então "transformar a realidade opressora é tarefa histórica, é tarefa de todos os homens" (FREIRE, 1970, p.20).

Como não poderia deixar de ser dentro da chave de uma dialética, a igualdade do sermais deve necessariamente passar por uma mediação que a concretize materialmente enquanto efetividade. Tal posição progressista, contudo, não se identifica plenamente com o discurso político denegando o vetor pedagógico. Ao contrário, a lucidez de Freire é exatamente mostrar como apenas através de um processo formativo outro, isto é, através de uma prática educativa que conteste em sua forma e conteúdo as dinâmicas de desigualdade e exploração próprias a nossa atual sociedade, que esse processo de emancipação pode se realizar. A educação, nesse sentido, vai na contramão da ordem social, pois dentro de uma ordem marcada estruturalmente pela servidão e heteronomia, uma educação que se queira emancipadora apenas pode ser uma educação que negue de forma determinada tal ordem. Tal negatividade exigida por uma prática educacional crítica nos lembra como, no fundo, não há povo. $O$ oprimido não é o povo, são as pessoas em suas singularidades. O povo, enquanto sujeito político, é aquilo que deverá ser autoproduzido ao fim do processo, na comum partilha de inteligências que visa a autonomia coletiva.

GIMBO, Fernando. Emancipação intelectual e democracia: para uma filosofia crítica da educação a partir de Jacques Rancière e Paulo Freire. Griot : Revista de Filosofia, Amargosa, Bahia, v.16, n.2, p.270-284, dezembro/2017. 
Hanna Arendt mostrou - em sua leitura da filosofia grega clássica (2013) - como a constituição de uma esfera pública dialógica é condição necessária, mas não suficiente, para o desenvolvimento da democracia. A democracia é um regime político que exige, antes de tudo, a formação de cidadãos capazes de tomarem a palavra em situação de igualdade de discernimento, poder de deliberação e reconhecimento social. Logo, a educação como forma de emancipação das inteligências e formação para autonomia é um vetor essencial a todo e qualquer projeto político democrático. Sem formação, como poderia haver sujeito cidadão? Como poderia existir vontade popular soberana? Novamente encontramos a pedagogia freiriana muito próxima da filosofia da educação de Adorno:

[...] gostaria de apresentar a minha concepção de educação. Evidentemente não a assim chamada modelagem de pessoas, porque não temos o direito de modelar pessoas a partir do seu exterior; mas também não a mera transmissão de conhecimentos, cuja característica de coisa morta já foi mais do que destacada, mas a produção de uma consciência verdadeira. Isto seria inclusive da maior importância política; sua ideia, se é permitido dizer assim, é uma exigência política. Isto é: uma democracia com o dever de não apenas funcionar, mas operar conforme seu conceito, demanda pessoas emancipadas. Uma democracia efetiva só pode ser imaginada enquanto uma sociedade de quem é emancipado (ADORNO, 1995, p.140-41).

Da convergência entre educação e política, entre emancipação intelectual e social, se tece a relação entre filosofia da história e educação que arma as bases para a boa compreensão da pedagogia do oprimido freiriana enquanto prática de emancipação. $\mathrm{O}$ reconhecimento do papel da educação na autodeterminação do povo enquanto sujeito político marca, dentro do pensamento de Freire, sua apresentação como a atividade de base na transformação do mundo. Em uma palavra, sua grande base normativa é o apelo a produção das condições para uma democracia real, regime político em que o poder soberano do povo institui seu próprio governo superando a situação de heteronomia que a contradição oprimido-opressores assinala.

Consequentemente, há um certo progresso histórico a ser conquistado e efetivado pelo sujeito político. Ou seja, na pedagogia freiriana a igualdade de inteligências tem somente ao final do processo - na concretização de uma democracia popular - a expressão concreta de sua verdade. Mas, como tentei argumentar, isso não significa uma oposição ao pensamento de Rancière, e sim uma complementariedade entre ambas as posições. A verdade é que Freire nos fala pouco sobre o ser-mais e devido à grande ênfase posta na contradição social, nos deixa, de certa forma, sem grandes recursos - sobretudo empíricos e antropológicos - para uma compreensão conceitual e mais ampla da ideia de uma inteligência comum que fundamente os processos pedagógicos em que "os homens se educam entre si mediatizados pelo mundo" (FREIRE, 1970, p.39). Por outro lado, Rancière, ao enfatizar por demais o princípio da igualdade a partir da releitura da experiência pedagógica de Jacotot, deixa um pouco de lado sua difícil mediação social e sua finalidade democrática institucional, encerrando-a em uma afirmação de cunho um pouco idealista. Ler conjuntamente Freire-Rancière nos auxilia a criar uma estrutura de reenvios que ilumina e enriquece ambas as posições criando um contraponto virtuoso em que a igualdade e democracia podem aparecer tanto como princípio, quanto como fim, da educação.

\section{Crítica e normatividade}

Axel Honneth (2000, p.11-69), em seu ensaio sobre a tradição e a atualidade da filosofia social, nos lembra como antropologia e filosofia da história foram durante todo o séc. XX recursos para a fundamentação de uma teoria crítica da sociedade. Por crítica devemos entender

GIMBO, Fernando. Emancipação intelectual e democracia: para uma filosofia crítica da educação a partir de Jacques Rancière 
aqui uma interrogação que ao se perguntar pelo contemporâneo realiza tanto diagnósticos de bloqueios à emancipação, quanto propõe soluções a esses mesmos bloqueios. Seguindo nessa direção, Honneth argumenta que durante todo o séc. XX antropologia e filosofia da história acabaram muitas vezes por se contraporem, a ponto de se enfrentarem como alternativas para a fundamentação de uma reflexão crítica. Por um lado, uma antropologia filosófica com forte carga normativa capaz de orientar os diagnósticos - dentro do campo social - de bloqueio para a efetivação das potencialidades humanas; por outro lado, uma filosofia da história que interpreta a humanidade dentro de seu devir-histórico, naquilo que se fez dela em seu próprio tempo e do que deveríamos fazer em vista de um futuro melhor.

Tendo tais coordenadas em vista, proponho que a leitura conjunta de Rancière-Freire permite uma síntese entre ambas as posições a partir do desenvolvimento de uma filosofia crítica da educação. Isso porque, como vimos, não é possível compreender a antropologia de Rancière sem recurso à contraposição da forma histórica de nossos aparatos educacionais; assim como pouco entendemos da perspectiva histórica de Freire sem passar pela contradição essencial entre o ser-mais inerente ao humano e a organização social que tende ao ser-menos. Em ambos os casos, antropologia e filosofia da história caminham juntas criando uma perspectiva normativa capaz de nos orientar quanto ao problema do sentido da educação a partir do atual arranjo social.

Quando falamos em normatividade entramos no campo da atividade racional que, descolando-se momentaneamente da realidade empírica, se pergunta pelo "dever ser" e não simplesmente por "aquilo que é". A reflexão normativa define-se pelo estabelecimento de ideias reguladoras que, ainda que nunca se realizem plenamente, balizam nossas práticas sociais evitando a perpetuação mecânica e sem sentido das normas já estabelecidas, no mesmo movimento em que realizam a expectativa da razão de relacionar meios e fins segundo as necessidades e demandas práticas. Por isso, uma teoria crítica não se reduz à mera descrição de fatos - como nas teorias positivistas - e nem mesmo à explicação causalista dos fenômenos. Inversamente, ela se determina pela constante tentativa de superação dos fatos através do uso autônomo da razão enquanto instância capaz de engendrar fins adequados à dignidade e liberdade humana (HORKHEIMER, 1983). Em outras palavras, a "negação daquilo que é" é feita a partir de um projeto emancipatório de "como deveria ser". É da distância, ou mesmo contradição, entre esses dois níveis que a crítica retira seu potencial transformador orientando a direção a ser dada ao desenvolvimento político, econômico e social.

A pergunta que se impõe, no nosso caso, é: através de qual fundamento, ou de quais princípios, podemos determinar de forma racional o "dever ser" da educação hoje? A resposta proposta, como vimos, passa tanto por uma compreensão antropológica das capacidades humanas quando pelo reconhecimento de seu possível papel histórico-político. É por isso que em Rancière-Freire o que encontramos, antes de mais nada, é uma reflexão crítica de filosofia da educação em que através de uma exposição aguda e rigorosa busca-se determinar não técnicas de ensino, mas sim a normatividade intrínseca aos processos de ensino e aprendizagem. Normatividade essa que insiste no caráter igualitário da inteligência $e$ na função democratizadora das instituições pedagógicas.

Tendo estabelecido tal entrelaçamento entre antropologia e filosofia da história, podemos agora realizar o movimento crítico por excelência de se perguntar sobre a possível realização de tais princípios normativos dentro da atual organização social.

\section{Capital humano e crescimento econômico}


Em seu curso de 1978 - O nascimento da biopolítica - Michel Foucault insistia que a forma de organização neoliberal da sociedade reconfigurava a compreensão moderna do sujeito: em uma sociedade cada vez mais determinada segundo a racionalidade do mercado aberto e seus imperativos de concorrência irrestrita e iniciativa privada, era a própria vida humana que se reduzia paulatinamente a determinadas variáveis quantitativas e ao cálculo utilitário ${ }^{9}$. $\mathrm{O}$ resultado era a decomposição analítica da população em termos estritamente ligados às suas capacidades de produção e consumo, isto é, em sua potencial contribuição para o aumento da atividade econômica total do país. Dentro desse quadro, o ser humano passava a ser essencialmente compreendido em termos de capital humano - competência, aptidões, valor cultural agregado, técnica, tempo de estudo, conexões com redes de pessoas e investimentos, capacidade de compra, etc - capital esse que nos daria o coeficiente médio da rentabilidade de suas ações enquanto agente interno ao mercado. Dito de forma abrupta, de seu próprio valor social.

Tendo estabelecido o mercado como o quadro geral de determinação da existência humana, Foucault insiste que o neoliberalismo acaba por criar consequentemente uma nova forma de antropologia normativa. À pergunta própria de toda antropologia filosófica - "o que é o homem?" - a "nova razão do mundo" propõe o modelo normativo do "empreendedor de si mesmo" (DARDOT e LAVAL, 2016). Daí a consequente universalização do modelo da empresa enquanto forma privilegiada de relação a si, como se o sujeito nada mais fosse do que um conjunto de competências com fins de reprodução incessante da vida material: "Uma economia feita de unidades empresas: é isso que é, ao mesmo tempo, o princípio de decifração ligado ao neoliberalismo e sua programação para a racionalização tanto de uma sociedade como de uma economia" (FOUCAULT, 2008, p.310).

A consequência de tal racionalização da sociedade é que todos os indivíduos serão compreendidos como potenciais empresários de si. O que nos permite dizer que a antropologia neoliberal é uma antropologia concorrencial de valorização do próprio capital entendido como vida rentável. Decomposição analítica da vida de uma população em termos econômicos e gerência feita através da incitação da competição tendo em vista o aumento da produção e do consumo, eis a lógica mais elementar do neoliberalismo enquanto dispositivo de administração social. As consequências de tal compreensão econômica do homem são inúmeras. Destaquemos apenas duas por elas estarem intimamente relacionadas com a nossa argumentação

Em primeiro lugar, vimos como a ideia de educação é indissociável de uma certa précompreensão sobre a humanidade. Sendo a educação um processo próprio ao ser do ente humano, a determinação essencial de tal ente acaba por determinar também a direção dos processos formativos e pedagógicos. Com o neoliberalismo assistimos uma expropriação da inteligência e de sua capacidade criativa segundo imperativos que não tomam o ser humano como um fim em si mesmo, mas como meio para o verdadeiro fim que seria a reprodução não problematizada do arranjo social. Por isso, como explica Rancière, uma discussão sobre a educação deve começar, antes de tudo, com uma disputa em torno da humanidade própria a homens e mulheres, uma disputa em torno do que devemos compreender por uma vida plena possível e o papel da educação nesse processo.

Sobre isso, Martha Nussbaum (2010) argumentou de forma notável como a obstrução de processos educacionais mais amplos e plurais, devido à pressão por resultados pedagógicos mecânicos e pela finalidade da produção massiva de mão de obra qualificada, acabam por empobrecer a existência humana contemporânea, instituindo o "ser-menos" como regra e a desigualdade essencial como fundamento para a divisão meritocrática de recursos. Dentro de

\footnotetext{
9 Tomo aqui a liberdade de referir e recuperar certas ideias trabalhadas no meu artigo sobre Foucault e o neoliberalismo (GIMBO, 2017).
}

GIMBO, Fernando. Emancipação intelectual e democracia: para uma filosofia crítica da educação a partir de Jacques Rancière e Paulo Freire. Griot : Revista de Filosofia, Amargosa, Bahia, v.16, n.2, p.270-284, dezembro/2017. 
uma sociedade em que a educação se torna mais um braço da economia, o desenvolvimento pleno da inteligência através do acesso irrestrito à cultura humanística, científica e artística tende a desaparecer. Com isso, o sujeito neoliberal acaba por se alienar de si assumindo irrestritamente os imperativos de mercado enquanto ideal de conduta para si e perante o outro. Todo o desenvolvimento pessoal passa a ser desenvolvimento profissional, as dimensões da cultura, da ética e da estética se tornam supérfluas e o pensamento crítico um entrave para a eficácia exigida pelo competitivo mercado de trabalho.

Ora, mas nesse caso, como poderíamos ainda sustentar qualquer noção de autonomia se o sujeito é levado a se formar e agir segundo condições e variáveis que ele não escolheu e sobre as quais não tem controle algum? A compreensão do ser humano enquanto capital humano institucionaliza uma concreta heteronomia sobre a ilusória autonomia da iniciativa privada. Mais do que isso, bloqueia o desenvolvimento amplo e irrestrito de nossas capacidades, mutilando o ser na exigência brutal de uma eficiência cega.

Na diferença entre ser-meio e ser-fim surge também a questão da dignidade e do direito. Pois, quando insistimos que a educação é um direito tal afirmação apenas pode ser compreendida sobre o fundo comum de entendermos que a vida humana digna passa pelo desenvolvimento de suas capacidades mais próprias, como a inteligência comum a todos. Quando abandonamos tal quadro, a consequência é a precarização das condições de realização da existência humana. Desfeito o laço entre dignidade, educação, direito e realização própria, a educação é lançada ao campo dos serviços segundo a lógica das desigualdades que estruturam todo e qualquer mercado. À razão pública sobraria o papel de ações emergenciais que visariam conter tais desigualdades, minimizando-as. $\mathrm{O}$ ciclo da impotência e o predomínio das políticas assistencialistas denunciadas por Freire e Rancière começam, doravante, o seu infinito ruim.

Em segundo lugar, como bem mostrou Wendy Brown (2015), a decadência de uma prática emancipadora da educação traz um imenso perigo à própria dinâmica democrática. Isso porque não há como pensar uma democracia que não esteja fundada - de direito - na autodeterminação política dos sujeitos. O problema é que, com a guinada neoliberal, a educação é reduzida basicamente a um "investimento" que tem em vista o esperado "retorno econômico". Quando o crescimento do PIB se torna a única justificativa e régua para as políticas de educação, então a própria democracia se encontra fragilizada, pois seu pilar de sustentação central - a formação do cidadão - é atacado. Submeter a formação do sujeito ao imperativo de crescimento econômico é destruir as condições mais elementares para a concretização efetiva de uma democracia social concreta.

O principal efeito de tratar a subjetividade, a escola e a universidade tal qual uma empresa é precisamente o divórcio entre educação e sua função política. A partir de então, uma nova ideologia da educação como desenvolvimento de "competências e habilidades" irá determinar em grande parte o rumo das discussões pedagógicas, assim como a tentativa de racionalizar a formação do indivíduo através de testes e avaliações meritocráticos irá predominar no debate especializado. $O$ ataque às humanidades e às artes, assim como o retraimento da importância do pensamento crítico na formação de cidadãos serão apenas efeitos de uma cadeia de medidas que visa a inscrição irrestrita de toda e qualquer subjetividade e instituição de ensino nas malhas dos imperativos econômicos. Com isso, a relação entre educação e política a partir das bases normativas de uma filosofia da história encontram-se bloqueadas.

\section{Emancipação e democracia}

O que tal descrição da racionalidade neoliberal nos permite ver é como a educação pode, mais do nunca, nos oferecer tanto princípios normativos quanto um programa de emancipação

GIMBO, Fernando. Emancipação intelectual e democracia: para uma filosofia crítica da educação a partir de Jacques Rancière 
para a sociedade contemporânea. Pois se entendemos a educação como um vetor formativo dos indivíduos e de suas relações intersubjetivas, então é preciso pensar segundo qual relação de meios e fins tais processos são estabelecidos. O que coloca a urgente questão de saber se realmente o mercado pode ser o espaço de ancoragem de toda e qualquer prática social.

Como espero ter deixado claro, a resposta deve ser francamente negativa. É preciso insistir como um conceito racional de educação pressupõe noções antropológicas e democráticas sem as quais ela se torna um mero dispositivo de perpetuação das fraturas e irracionalidades próprias à sociedade contemporânea, desfigurando-se essencialmente e perdendo sua vocação emancipatória.

Recuperar uma ideia humanista de formação - não em termos de uma essencialidade própria ao "homem" - mas sim fundada na ideia da igualdade em potência das inteligências é uma forma de propor, da base, uma compreensão da educação capaz de criticar os pressupostos da ideia de capital humano. No mesmo movimento, recuperar a relação entre educação e filosofia da história é uma maneira de insistir na necessária relação entre política e educação tendo em vista a concretização de uma democracia real.

Através de uma leitura conjunta das obras de Jacques Rancière e Paulo Freire o que podemos desenvolver é uma filosofia da educação que oriente não apenas nossas práticas educacionais, mas também e sobretudo que fundamente e direcione de forma imanente nossa crítica do capitalismo contemporâneo. O que revela como a educação é um campo da experiência humana profundamente avesso à subsunção aos imperativos da economia. Saber tirar disso a energia emancipatória necessária é um imperativo maior para toda e qualquer discussão sobre filosofia da educação no séc. XXI. 


\section{Referências bibliográficas}

ADORNO, T. Educação e emancipação, Rio de Janeiro, Paz e Terra, 1995.

ARENDT, H. Origens do totalitarismo, São Paulo, Companhia de bolso, 2013.

ALTHUSSER, L. Aparelhos ideológicos de Estado, Rio de Janeiro, edt. Graal, 1992.

BORDIEU, P. La distinction. Critique social du jugement, Paris, Les éditions du minuit, 1979.

BROWN, W. Undoing the demos: neoliberalism's stealth revolution, New York, Zone Books, 2015.

DARDOT e LAVAL, A nova razão do mundo: ensaio sobre a sociedade neoliberal, São Paulo, edt. Boitempo, 2016.

ESPINOSA, B. Tratado da emenda do intelecto, in. Col. Os Pensadores, São Paulo, Abril Cultural, 1983.

FOUCAULT, M O nascimento da biopolítica, São Paulo, Martins Fontes, 2011.

FREIRE, P. Pedagogia do oprimido, Rio de Janeiro, edt. Paz e Terra, 1970.

GIMBO, F. Uma arqueologia do mercado: Foucault e o neoliberalismo como dispositivo biopolítico, in. Revista Kalagatos, v.14, 2017.

HONNETH, A. Das Andere der Gerechtigkeit. Aufsäte zur praktischen Philosophie, Frankfurt am Main, Suhrkamp, 2000.

HORKHEIMER, M. Teoria tradicional e teoria crítica, in. Coleção os pensadores, São Paulo, Abril Cultural, 1983, p.117-154.

KANT, I Resposta à pergunta: $O$ que é esclarecimento?, in. Kant: t 005C'extos selecionados, páginas 63-71, São Paulo, edt. Vozes, 2005.

NUSSBAUM, M. Not for profit: why democracy needs the humanities, New Jersey, Princeton University Press, 2010.

RANCIÈRE, J. O mestre ignorante: cinco lições sobre a emancipação intelectual, Belo Horizonte, edt. Autêntica, 2011.

ROUSSEAU, J. Discurso sobre a origem e os fundamentos da desigualdade entre os homens, São Paulo, Martins Fontes, 2005.

SEN, A. Development as freedom, New York, Borzoi Book, 1999.

Autor(a) para correspondência: Fernando Gimbo, Universidade Federal do Cariri, R. Ten. Raimundo Rocha, s/n, Cidade Universitária, CEP 63048-080, Juazeiro do Norte - CE, Brasil. sepefernando@gmail.com 